\title{
UNA COMPAÑIA TEATRAL EN BOGOTÁ EN 1618
}

El contrato ${ }^{1}$ abajo reproducido, inédito hasta ahora, merece conocerse por ser el primero y por la luz que derrama sobre los actores y actrices que representaban piezas teatrales en Santa Fe de Bogotá en 1618. Son tan escasas las noticias del siglo xvir relativas al teatro bogotano ${ }^{2}$, que cualquier nuevo dato de este período constituye una novedad de importancia; nuestro documento la tiene además porque proporciona información acerca de una compañía de cómicos, quizá la primera organizada en la futura capital de Nueva Granada. La escritura revela también que los grupos dedicados a representar comedias solían viajar, como cosa del oficio, de una colonia a otra.

El 3 de noviembre de 1618 aparecieron ante el escribano Pedro de Bustamante ocho actores y actrices: Martín Calvo y su esposa María de Sandoval ${ }^{3}$, de una parte; y de la otra Francisco de Medrano ${ }^{4}$, Pedro Caro Velásquez, Luis de Granados, Diego de Zúñiga y Bayas ${ }^{5}$, Pedro Corbín y Juana de los Reyes ${ }^{6}$, viuda de Miguel Burillo. Manifestaron la intención de formar una sola compañía, constituída por un período de tres años desde la fecha, y convinieron en trabajar juntos en todas partes, no disolver la agrupación durante el tiempo estipulado y no admitir nuevos socios sin acuerdo de todos. Había multas para los desertores, asistencia colectiva a prorrata en caso de enfermedad o de prisión por causas justas, y anticipos por las deudas personales.

Por su trabajo Martín Calvo y su esposa María de Sandoval habían de recibir de partido7 "veinte y dos reales castellanos sencillos". Los demás — con la excep-

1 Conservado en el Archivo Nacional de Colombia, Protocolo de la Notaría $2^{\text {a }}$ de Bogotá, tomo XIX, folios 318r- 321r. Quiero expresar aquí mi profunda gratitud a mi estimado amigo don Enrique Ortega Ricaurte, jefe del Archivo Nacional de Colombia, por haberme proporcionado una fiel copia del manuscrito original.

2 La noticia más antigua se remonta al año 1580 , cuando dos cómicos entraron en Santa $\mathrm{Fe}$ de Bogotá a representar un sainete titulado Los Alarcos, parte de la función dispuesta para festejar la llegada de los obispos de Santa Marta y Cartagena, reunidos allí para el concilio convocado por el arzobispo Zapata. El Presidente del Concilio, don Antonio González, fué recibido en Bogotá, en marzo de 1590, con diversiones públicas, corridas de toros y comedias. Cuatro años después, en 1594, unos aficionados al teatro, residentes en la ciudad, organizaron una compañía que dió representaciones en un improvisado tablado bajo toldas. El mismo año en que se formó la compañía que ocupa nuestra atención, Bruno de Valenzuela, primer dramaturgo identificado hasta ahora, compuso su comedia religiosa Vida de hidalgos, estrenada con éxito al año siguiente en España y Bogotá. Véanse José Vicente Ortega Ricaurte, Historia crítica del teatro en Bogotá, Bogotá, 1927, págs. 3-7; Pedro M. IвÁN̂Ez, Las crónicas de Bogotá y de sus inmediaciones, Bogotá, 1891, pág. 48.

3 Martín Calvo, natural de Sevilla e hijo de Cristóbal Martínez Calvo y Catalina Flores, se casó en la ciudad de Guatemala con María de Sandoval, que trabajó junto con su consorte en los escenarios limeños. Actuaban en Lima desde 1621 en adelante. El 28 de febrero de 1626 María de Sandoval se comprometió a hacer "todos los papeles assí de hombre como de muger para comedias y entremeses". En 1626 Calvo servía de carcelero en la cárcel pública de Lima. Murió el 16 de julio de este año. Véase Guillermo Lohmann Villena, El arte dramático en Lima durante el virreinato, Madrid, 1945, págs. $160,166,175,180,195-196$ y 611.

4 Francisco de Medrano nació en 1578. Actuaba en Lima en 1611 con la compañía dirigida por Miguel de Burgos. Ibid., págs. 121 y 615.

5 Diego de Zúñiga y Bayas trabajaba en Lima en 1626. Ibid., pág. 197.

6 Juana de los Reyes, después de 1625, hizo el papel de Sirena en Celos con celos se curan de Tirso de Molina. Véase Hugo Albert Rennert, The Spanish Stage in the Time of Lope de Vega, New York, 1909, pág. 569.

7 Mesonero Romanos explica lo que era el partido: “...el empresario, que suele ser un actor antiguo o un individuo unido al teatro por lazos de consanguinidad, reúne las partes que le convienen, y sin más adelanto que el preciso para gastos del viaje y algunos días de asistencia a toda la compañía, cobra después durante las funciones de todo el año el 25 por 100 o más del capital adelantado; y para 
ción de Pedro Corbín y Juana de los Reyes, a quienes se asignaban ocho reales hasta el día de Corpus Christi de 1619, y nueve después de esta fecha ganarían diez reales. La compañía esperaba quedarse en Bogotá hasta celebrado el Corpus, y salir luego para el Perú y la Nueva España. Martín Calvo, como director, cobraría el dinero y tendría a su cargo las cuentas y los otros negocios relacionados con la compañía, con autorización para todo; los demás obligaban sus personas y sus bienes, presentes y futuros, para la ejecución del contrato. Las dos actrices renunciaban a los derechos conferidos por las leyes especiales para mujeres. María de Sandoval jura que entra en el contrato de su propia voluntad y que las estipulaciones no le perjudican "por razón de su dote, arras ni bienes parafernales". Ni ésta ni Diego de Zúñiga sabían escribir; un testigo firmó la escritura por ellos. Así quedó legalizada la formación de una compañía de cómicos, la primera de que tenemos hasta ahora noticia para aquella colonia.

«En la ciudad de Santafé del Nuevo Reino de Granada de las Indias, a tres de noviembre de mil y seiscientos y diez y ocho años, ante mí el Escribano de Su Magestad y testigos infrascritos, Martín Calvo y doña María de Sandoval, su legítima mujer, con su licencia y expreso consentimiento que para otorgar la presente le pide y concede, de la una parte, y Francisco de Medrano, Pedro Caro Velásquez, Luis de Granados, Diego de Zúñiga y Bayas, Pedro Corbín e Joana de los Reyes, viuda de Miguel Burillo, de la otra, y dijeron que hacen y celebran compañía en esta manera: Que todos juntos estarán en compañía, sin dividirse unos de otros en manera alguna, tiempo de tres años, que corren y se cuentan desde hoy dicho día, y así en esta ciudad, como en las demás partes donde estuvieren, representaran todas las comedias que están puestas y se pusieren adelante, sin poner en ello excusa alguna, asistiendo a las dichas comedias y representaciones que se hicieren, salvo por impedimiento justo o otra causa que lo impida.

»Y con condición que durante el dicho tiempo no se ha de desagregar la dicha compañía, ni recibirse a ella ningún compañero sin voluntad y acuerdo de todos juntos.

»Y con que ninguno de los dichos compañeros se ha de pasar a otra compañía, ni irse a otra parte, aunque se le siga mayor interés del que se le diere y hubiere de haber por esta compañía, so pena que el que lo contrario hiciere, incurra por ello en doscientos pesos de oro de veinte quilates, la mitad para la Cámara de Su Magestad, y la otra para la parte obediente, con más de que pague todas las costas, daños, intereses y menoscabos que se causaren y recrecieren a esta compañía por no cumplir con el tenor de ella, y la dicha pena pagada o graciosamente remitida, esta escritura y sus cláusulas se lleven a debida ejecución y vía ejecutiva y para que se consiga contra los que contravinieren a lo sobredicho baste solamente el simple juramento de cualquiera de los dichos compañeros, sin que sea necesario otra diligencia, prueba, ni averiguación de que se relevaron.

»Y durante el tiempo de los dichos tres años, cualquiera de los dichos compañeros que tuviere alguna enfermedad o alguna prisión que sea justa, los demás compañeros sean obligados rata por cantidad, como les cupiere, a darles sus partes que le cupieren de esta compañía como si para devengarlas las sirviera.

» $\mathrm{Y}$ con condición que todas las deudas que debieren los compañeros de esta

hacer el reparto del producto de aquéllas con proporción, se figura a cada individuo lo que se llama partido; v. gr.: A, primer galán, entra con partido de 40 reales; B, con 30, y C, con 20; siendo la entrada 225 reales, tocará al primero 100 reales, al segundo 75, y 50 al tercero, a razón de dos partes y media..." Véase Ramón de Mesoneros Romanos, Los cómicos en Cuaresma, en Panorama matritense, (Obras), Madrid, s. a., I, págs. 62-63. 
compañía, o cualquiera de ellos, causadas hasta el día de hoy en esta ciudad de Santafé, se hayan de pagar y paguen de esta dicha compañía, rata por cantidad como está referido, entre todos, con que, si después de pagadas las dichas deudas no alcanzare el tal compañero con las partes que le cupiere, sea obligado a pagar y satifacer a la dicha compañía lo que debiere de más a más a los tiempos y plazos que cómodamente pudiere.

»Y lo que cada uno de los dichos compañeros ha de haber de partido durante el dicho tiempo de tres años es lo siguiente:

»El dicho Martín Calvo y su mujer, veinte y dos reales castellanos sencillos.

»Luis de Granados, Francisco de Medrano, Pedro Cano y Diego de Zúñiga, a diez reales cada uno de parte.

»Y los dichos Pedro Corbín y Juana de los Reyes, a ocho reales cada uno, desde hoy dicho día hasta el día de Corpus que viene de seiscientos y diez y nueve, que es el tiempo que han de asistir en esta Corte, y pasado este tiempo, se les ha die dar a cada uno de los dichos Pedro Corbín y Juana de los Reyes a nueve reales, y este dicho partido no se pueda aumentar ni diminuir a ninguno de los dichos compañeros.

»Y con condición que para el dicho día de Corpus Criste o ocho después, hayan de salir y salgan de esta dicha ciudad de Santafé y Reino para los del Perú y Nueva España.

»Y con condición que todo el dinero que se hiciere haya de entrar y entre en poder del dicho Martín Calvo para que por su mano pague lo que a cada uno le tocare y las deudas que debiere; y para la ejecución y cumplimiento de todo ello las dichas partes, por lo que a cada uno toca, obligaron sus personas y todos sus bienes habidos y por haber, y dieron poder a las justicias de Su Magestad, donde esta escritura fuere presentada, de cualesquier partes y lugares que sean, a cuyo fuero se sometieron, renunciaron el suyo propio y otro que ganen, y sobre ello la ley sit cumvenerit de jurisdictione omnium judicum y última premática de sumisiones para la ejecución de ello, como de sentencia pasada en cosa juzgada; renunciaron las leyes de su favor, la general ${ }^{8}$, y las dichas doña María de Sandoval y Juana de los Reyes el auxilio del Veleyano ${ }^{9}$, nueva constitución ${ }^{10}$, leyes de Toro ${ }^{11}$ y partida ${ }^{12}$, de cuyo efecto

8 "Derechos generales de la ley. Son las tachas señaladas por la ley a los testigos, las cuales desvanecen o disminuyen tan sólo su fuerza de deposición. Se llaman generales, porque estas preguntas a las cuales deben someterse los testigos son formuladas por los jueces indistintamente y constituyen, juntamente con las preguntas llamadas especiales o útiles, el interrogatorio indispensable al abrir una causa. Constituyen las tachas citadas la menor edad de los testigos, amistad o parentesco con las partes, así como también la enemistad o el odio, interés en la causa, el deseo de que gane una de las partes, etc." Véase Enciclopedia universal ilustrada, Barcelona, XXV, pág. 1221.

9 Veleyano: un senadoconsulto romano que prohibía a las mujeres el obligarse como fiadoras por persona alguna. Véanse Alexand. Scoti et Jo. Gottr. Heineccir, Vocabularium juris utriusque, Bousquetiana, 1759, III, 516; Exías Zerolo, Diccionario enciclopédico de la lengua castellana, nueva edición, Paris, s. a., II, 984.

10 El licenciado Bartholomé de Arrieta, comisionado por Felipe II, fué el redactor de una compilación en nueve libros de ordenamientos de Cortes y órdenes reales, que se llamó Nueva recopilación. El rey la promulgó en 1567. En ella se quería codificar parte del derecho general de Castilla y, hasta cierto punto, de toda España. Véase Rafael Altamira, Historia de España y de la civilización española, 3a edición, Barcelona, 1913, III, 328-331.

11 Las Leyes de Toro, acordadas en las Cortes de Toledo de 1502, fueron publicadas en 1505. Con las ochenta y tres leyes de esta compilación se realizó la reforma legal del derecho privado. "En punto a la mujer casada, se fija minuciosamente su falta de personalidad jurídica, dependiendo de la licencia del marido en casi todos sus actos,... Aunque explícitamente no lo dice ninguna ley, se ve, por diferentes alusiones, que ya entonces se había introducido la forma de la dote romana, es decir, de la dote aportada por la mujer (como disponían las Partidas), subsistiendo la antigua del marido, que ya vino a designarse especialmente con el nombre de arras que de antiguo tenía". Ibid., II, 441-443.

12 Es decir, Las siete partidas. 
fueron avisadas por el presente Escribano, y como sabidoras y enteradas de ellas, las renuncian y apartan de su favor para no se aprovechar de ellas en manera alguna, y la dicha doña María de Sandoval juró por Dios Nuestro Señor sobre una señal de cruz de haber por firme esta escritura y de no ir ni venir contra ella en manera alguna, por razón de su dote, arras ni bienes parafernales, ni mitad de multiplicado, ni por otro derecho que le competa, alegando que para la hacer ha sido atemorizada, ni que se le ha hecho fuerza ni premia alguna, porque ninguna de estas causas han precedido, antes declara que el efeto de esta escritura se convierte en su utilidad y provecho, y contra el dicho juramento no pedirá absolución, ni relajación del dicho juramento a ningún juez, ni perlado que poder tenga de se lo conceder, y caso que se le conceda, no usará della en manera alguna, so pena de perjura e infame y de las otras del derecho, y a los dichos otorgantes, doy fe, conozco, que lo firmaron, y por los dichos Diego de Zúñiga y doña María de Sandoval un testigo, porque dijeron no saber, siéndolo Fernando de Aguilera, Miguel Sánchez de Villoslada y Pedro de Lascuraín.

»Martín Calvo. Francisco de Medrano. Luis de Granados. Pedro Caro Velásquez. Pedro Corbín. A ruego de Diego de Zúníiga y por testigo, Hernando de Aguilera. Juana de los Reyes. »Ante mí, Pedro de Bustamante».

Northwestern University.

HARVEY L. Johnson Evanston, Illinois. 